\title{
Comparative Study of Two Root Coverage Procedures: A 24-Month Follow-Up Multicenter Study
}

Ofer Moses, * Zvi Artzi, * Anton Sculean, ${ }^{\dagger}$ Haim Tal, * Avital Kozlovsky, * Georgios E. Romanos, ${ }^{\ddagger}$ and Carlos E. Nemcovsky* $\S$

Background: Treatment alternatives to cover exposed root surfaces include free grafts, pedicle flaps, and barrier membranes. This 24 -month follow-up study clinically evaluated the long-term effect of a coronally advanced flap procedure with the additional use of enamel matrix derivative (EMD) to treat gingival recession versus the subpedicle connective tissue graft (CTG) procedure.

Methods: Miller Class I or II buccal recession-type defects in the anterior teeth or premolars in 65 patients (28 in EMD and 37 in CTG groups) were treated in several centers. At baseline and 12 and 24 months post-treatment, vertical recession defect (VRD), height of keratinized tissue (HKT), and probing depth (PD) were recorded, and the percentage of root coverage (PRC) of the original defect was calculated. Student $t$ test, analysis of variance, and analysis of covariance were used for statistical analyses.

Results: At 12- and 24-month evaluations, PRC was 73.2\% $(\mathrm{SD}=15.58 \%)$ and $76.9 \%(\mathrm{SD}=16.77 \%)$ in the EMD group and $86.8 \%(S D=12.48 \%)$ and $84.3 \%(S D=13.32 \%)$ in the CTG group, respectively $(P<0.001)$. Differences between groups were statistically significant $(P=0.002)$. Baseline HKT was $1.07 \mathrm{~mm}(\mathrm{SD}=0.66 \mathrm{~mm})$ in the EMD group and $1.65 \mathrm{~mm}(\mathrm{SD}=0.92 \mathrm{~mm})$ in the CTG group. At 12 and 24 months, values were $1.75 \mathrm{~mm}(\mathrm{SD}=0.59 \mathrm{~mm})$ and 2.25 $\mathrm{mm}(\mathrm{SD}=0.52 \mathrm{~mm})$ in the EMD group and $4.24 \mathrm{~mm}(\mathrm{SD}=$ $0.89 \mathrm{~mm})$ and $4.05 \mathrm{~mm}(\mathrm{SD}=0.94 \mathrm{~mm})$ in the CTG group, respectively. Differences in HKT were statistically significant within (EMD: $P<0.001$; CTG: $P=0.017$ ) and between $(P<0.001)$ groups.

Conclusions: Both treatments proved clinically successful. CTG treatment showed a higher percentage of root coverage and HKT increase. EMD is a valuable, long-term effective treatment alternative to achieve root coverage together with an increase in HKT. J Periodontol 2006;77:195-202.

\section{KEY WORDS}

Enamel matrix proteins; gingival recession/surgery; surgical flaps; tooth.

\footnotetext{
* Department of Periodontology, The Maurice and Gabriela Goldschleger School of Dental Medicine, Tel Aviv University, Tel Aviv, Israel.

$\dagger$ Department of Periodontology, Radboud University Medical Center, Nijmegen, The Netherlands.

‡ Department of Implant Dentistry, College of Dentistry, New York University, New York, NY

$\S$ Dental and Maxillofacial Center, Souraski Tel-Aviv Medical Center, Tel-Aviv, Israel.
}

$\mathrm{N}$ umerous periodontal plastic surgical procedures have been proposed for the treatment of gingival recession, including free grafts, regeneration with use of barrier membranes, and pedicle flaps. ${ }^{1}$ An additional surgical site is required for the free graft procedure, thus causing discomfort to the patient. The use of free connective tissue grafts (CTG) to increase the width of keratinized gingiva was first introduced by Edel in 1975. 2,3 This procedure has shown high degrees of short- and long-term success in root coverage for Miller Class I or Class II marginal tissue recession, ${ }^{4,5}$ ranging from $80 \%{ }^{6,7}$ to $98.4 \%{ }^{8}$ Furthermore, the free graft procedure presents high predictability in root coverage and excellent esthetic results ${ }^{9}$ and is considered the standard used to evaluate other root coverage techniques. The need for a second surgical site to procure the donor tissue can be obviated by the use of an allograft in the form of acellular dermal matrix. ${ }^{10}$ However, in a long-term follow-up of single-tooth gingival recession defects treated with an acellular dermal matrix, a mean of only $50 \%$ root coverage was recorded. ${ }^{11}$

Barrier membranes have been applied to obtain root coverage together with periodontal regeneration. ${ }^{12-19}$ Results with these root coverage procedures vary from $54 \%$ to $87 \%$ (mean $=74 \%) .20$ A long-term study has shown that a good result of $92.3 \%$ in root coverage,

doi: 10.1902/jop.2006.050008 
measured at 6 months, decreased to $58.8 \%$ after a mean follow-up of 25.3 months. ${ }^{21}$

The coronally advanced flap, a relatively easy technique that allows acceptable predictable root coverage and esthetic results, does not require harvesting of the tissue grafts from a donor area. ${ }^{22-32}$ The amount of root coverage varies from $70 \%$ to $99 \%$ (mean = $83 \%){ }^{20}$

Periodontal regeneration has been induced in experimental human buccal dehiscence defects with enamel matrix derivative (EMD). ${ }^{33,34}$ Recently, clinical studies have shown the possibility of combining EMD with a coronally positioned flap procedure $\mathrm{e}^{30-32,35-38}$ to achieve coverage together with periodontal regeneration of the previously exposed root surface. A recent histologic evaluation of the coronally advanced flap with EMD has shown new cementum, organizing PDL fibers, and islands of bone at a certain distance from the root surface. ${ }^{36}$ Periodontal regeneration has been demonstrated following coronally repositioned flap procedures with the addition of EMD and not with a similar procedure without the addition of EMD. ${ }^{38}$ However, the histologic outcome of combining a subpedicle CTG with EMD is still not completely elucidated. ${ }^{39,40}$

The aim of the present study was to evaluate the long-term clinical efficacy of a coronally advanced flap with the addition of EMD for treatment of gingival recession versus the subpedicle CTG procedure.

\section{MATERIALS AND METHODS}

Patients willing to participate in the study signed an informed consent form. The appropriate ethics committees approved the study. Consecutive patients were treated in the study centers by seven different periodontists. All study centers had the same inclusion criteria: teeth with a good occlusal relationship, free from decay or buccal restorations, no previous periodontal surgical treatment, and no radiographic signs of periapical infection. Sites with probing depths (PD) $>3 \mathrm{~mm}$ or poor oral hygiene were excluded, as well as patients with systemic contraindications for periodontal surgery, under medication for high blood pressure and/or taking anticoagulants, and heavy smokers (>10 cigarettes per day). Because no calibration was performed prior to the study, intra- and interexaminer variability cannot be discarded.

For a patient with more than one treated tooth, only the tooth with the largest gingival recession was considered for the study. Patients were monitored in oral hygiene and instructed to achieve satisfactory plaque control. The treating surgeon randomly decided the procedure for each patient before baseline measurements were taken. However, no definite criteria were established for this decision. In the absence of keratinized tissue, a CTG procedure was always performed.
Thus, there were an unequal number of patients in each group. Treatment at each center was provided for approximately the same number of patients in both groups.

Between October 2001 and September 2002, the study included 65 consecutive patients, referred for treatment with Miller Class I or II buccal recessiontype defects in the anterior or premolar region, who were available for the 12- and 24-month follow-up measurements. The CTG group consisted of 26 females and 11 males, and the EMD group consisted of 18 females and 10 males, ranging in age from 17 to 59 years (mean $=36.8$ years; $S D=9.94$ years).

\section{Measurements}

The vertical recession defect (VRD), height of keratinized tissue (HKT), and PD were recorded at baseline (before treatment) (Figs. 1A, 1B, 2A, and 2B) and 12 and 24 months post-surgery. VRD was defined as the distance between the cemento-enamel junction (CEJ) and the free gingival margin at the mid-buccal aspect of the tooth. Where the CEJ was not evident due to tooth abrasion, its location was estimated. All measurements were taken from the most apical enamel present to the gingival margin. The estimated abraded area was registered and deducted from the measurement to calculate VRD. Because measurements were taken by the treating periodontist, the treatment group was known. A millimeter graded periodontal probe, estimated to the nearest 1 -mm mark, was used for all measurements. Therefore, measurement error was in the range of 0.5 to $1.0 \mathrm{~mm}$. Percentage of root coverage (PRC) of the original defect was calculated by the formula: ([VRD baseline - VRD postoperation]/VRD baseline) $\times 100$.

Results were statistically analyzed using $t$ test, analysis of variance (ANOVA) with repeated measures, and analysis of covariance (ANCOVA). Differences between centers were not statistically analyzed because of the small sample.

\section{Surgical Procedures}

Coronally positioned flap procedures. After local anesthesia, root debridement with ultrasonic and hand instruments was carried out. An intrasulcular incision was made with a \#15 C blade on the buccal aspect of the involved tooth. The adjacent papillae were only partially involved to preserve all soft tissue and to leave the buccal gingival margin of the adjacent teeth intact. A frenum pull (when present) was eliminated before surgery. Two oblique releasing incisions were made from the mesial and distal extremities of the intrasulcular buccal incision beyond the mucogingival junction. The facial portion of the gingival tissue that remained attached to the proximal teeth and proximal to the vertical incisions was deepithelialized to create a connective tissue surface. The full-thickness 

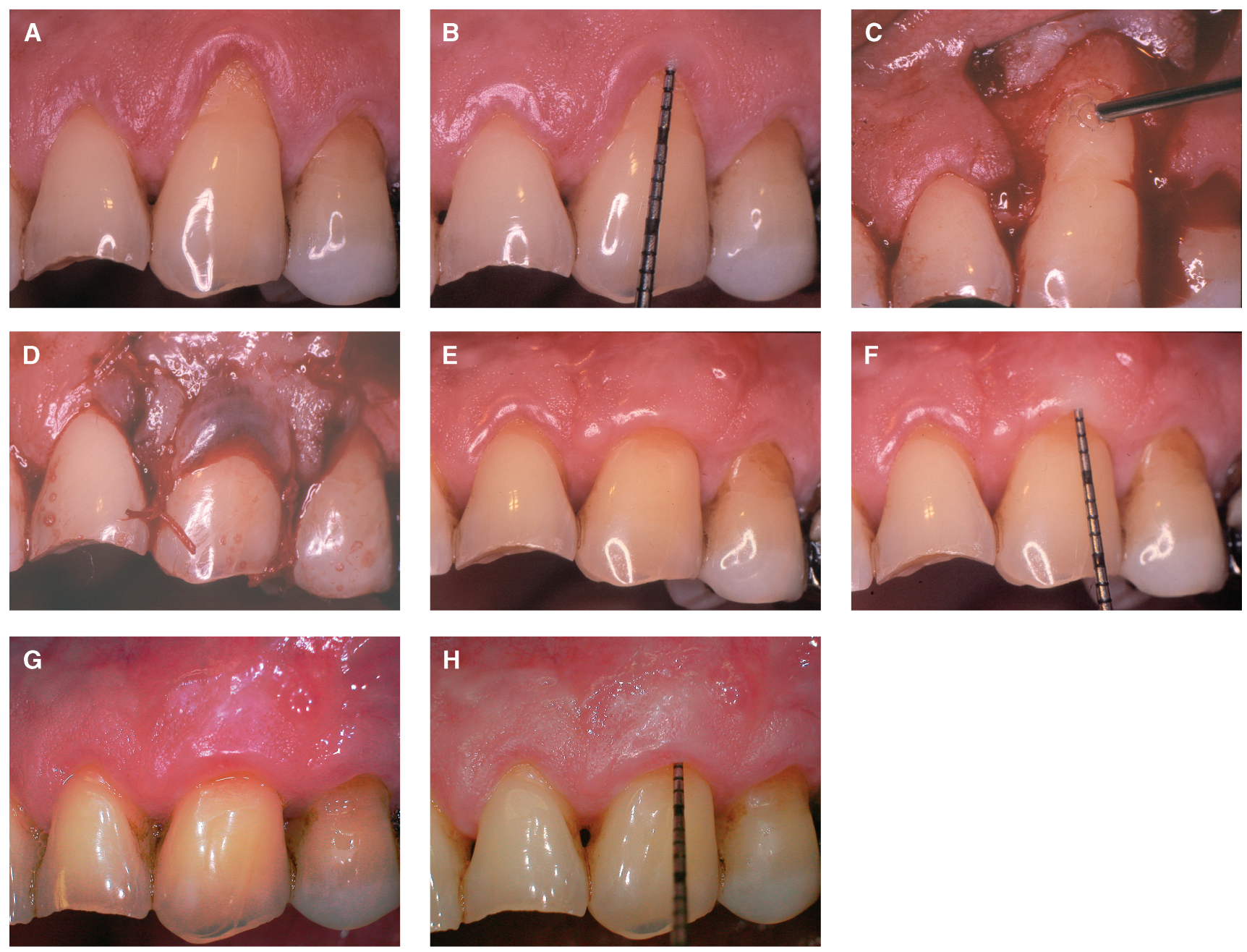

\section{Figure I.}

A) Preoperative aspect of maxillary left canine (EMD group). B) Periodontal probe illustrates degree of root exposure. C) Enamel matrix derivative being applied on denuded root surface. D) Final sutures following EMD procedure. E) 12-month follow-up; note degree of root coverage. F) 12-month follow-up with periodontal probe; note shallow probing depth. G) 24-month follow-up. $\boldsymbol{H}$ ) 24-month follow-up showing shallow probing depth. (A through $\mathrm{H}$ show the same tooth from one patient.)

trapezoidal flap exposed the marginal bone of the dehiscence on the root surface $\geq 3 \mathrm{~mm}$. The exposed root surface was additionally planed in the most coronal area using ultrasonic and hand instruments. A horizontal releasing incision was made in the periosteum at the base of the flap to allow tension-free coronal flap displacement. The root surface was conditioned with $24 \%$ EDTA gell for 2 minutes, copiously rinsed with running tap water or saline, dried with a gauze sponge, and EMD applied (Fig. 1C), starting from the most apical bone level and covering the entire root surface. The coronally positioned flap was secured coronally to the level of the CEJ by suturing to the papilla regions and the vertical releasing incisions to the proximal tissues and over the contact points (Fig. 1D) using either $4 / 0$ undyed, braided, coated polyglycolic acid suture ${ }^{\#}$ or $4 / 0$ polyglactin * * 910 suture.
After suturing, another increment of EMD was placed on the buccal root surface under the advanced flap by inserting the syringe needle between sutures through one of the lateral releasing incisions.

Subpedicle CTG procedures. After local anesthesia, the root surface was planed with ultrasonic and hand instruments. A frenum was eliminated before the surgical procedure. An intrasulcular incision was made with a \#15 C blade on the buccal aspect of the involved tooth. Interdental papillae were left untouched when possible. Horizontal incisions were made mesial and distal to the defect at the approximate level of the CEJ, which terminated $\geq 1 \mathrm{~mm}$ away

\| Prefgel, Straumann Biologics, Waldenburg, Switzerland.

If Straumann Biologics.

\# Surgical Specialties, Reading, PA.

** Johnson E Johnson International, Brussels, Belgium. 

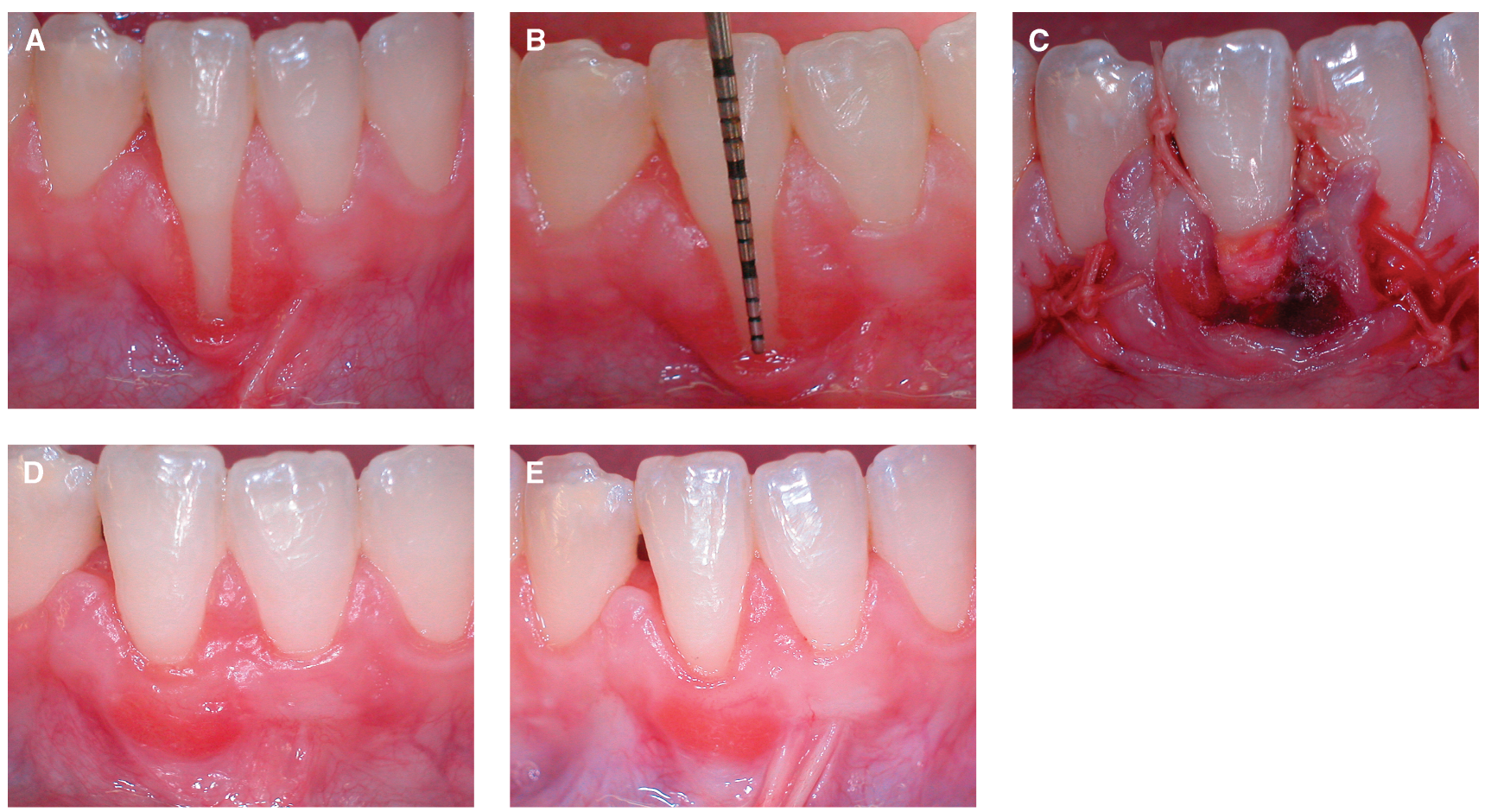

Figure 2.

A) Preoperative aspect of mandibular right central incisor (CTG group). B) Periodontal probe illustrates degree of root exposure; note absence of keratinized mucosa. C) Final sutures following CTG procedure; free connective tissue graft remained partially exposed. D) I2-month follow-up; note degree of root coverage and increased keratinized tissue width compared to baseline. E) 24-month follow-up. (A through E show the same tooth from one patient.)

from the gingival margin of the proximal teeth to avoid gingival recession. A trapezoidal flap was delineated with vertical incisions, starting at the end point, perpendicular to the horizontal incisions, and extending beyond the mucogingival junction. The flap was raised through sharp dissection as close to the periosteum as possible to a level that allowed its free coronal displacement. A connective tissue graft was procured from the palate in the premolar and first molar areas using parallel incisions or the trap door technique. The graft was trimmed, if necessary, and fixed by suturing in the recipient site with either $4 / 0$ to $5 / 0$ undyed, braided, coated polyglycolic acid suture ${ }^{\dagger \dagger}$ or $4 / 0$ polyglactin 910 suture ${ }^{\ddagger}$ bioabsorbable material. The pedicle flap was sutured over the CTG. Some coronal repositioning was always carried out, but there was no intent to cover the whole graft. In most cases, a variable portion of the connective tissue free graft remained uncovered (Fig. 2C).

Postoperative care was similar for both groups: to refrain from oral hygiene measures on the treated areas for 10 to 12 days and to avoid excessive muscle traction and chewing on or trauma to these areas. Chlorhexidine digluconate mouthwash, $0.12 \%$ or $0.2 \%$, was prescribed twice daily during that time. Analgesics were prescribed when necessary. On days
10 to 12 , the remaining sutures were removed, and the patient was instructed to brush with an extra soft toothbrush dipped in the chlorhexidine digluconate mouthwash. There were no complications and all patients experienced only minor postoperative discomfort. Patients were recalled after 3 months and subsequently once every 3 to 5 months until the final examination (at 24 months). During follow-up visits, patients had a professional supragingival tooth cleaning if necessary. Measurements were taken at 12 - and 24-month postoperative follow-ups (Figs. 1E through $1 \mathrm{H}, 2 \mathrm{D}$, and $2 \mathrm{E})$.

\section{RESULTS}

In the EMD and CTG groups, the mean age was 36.8 years $(S D=9.94$ years $)$ and 38.9 years $(S D=12.68$ years), respectively. Differences were not statistically significant ( $t$ test). Preoperatively, VRD and PD were similar in both groups (differences not significant), and HKT was significantly different $(P=0.021)$ between groups ( $t$ test) (Table 1 ).

No statistically significant interaction between treatment center and outcomes for any of the parameters

$\dagger \dagger$ Emdogain, Straumann Biologics. $\neq \ddagger$ Surgical Specialties. 
Table I.

Measured Values for VRD, HKT, PD, and PRC

\begin{tabular}{lcccccc}
\hline & \multicolumn{2}{c}{ Preoperative } & \multicolumn{2}{c}{ 12 Months } & \multicolumn{2}{c}{24 Months } \\
\cline { 2 - 6 } & EMD & CTG & EMD & CTG & \multicolumn{1}{c}{ EMD } & CTG \\
\hline VRD $(\mathrm{mm})$ & $4.29 \pm 1.10$ & $4.57 \pm 0.99$ & $1.18 \pm 0.72$ & $0.59 \pm 0.55$ & $1.0 \pm 0.72$ & $0.7 \pm 0.57$ \\
HKT $(\mathrm{mm})$ & $1.07 \pm 0.66$ & $1.65 \pm 0.92$ & $1.75 \pm 0.59$ & $4.24 \pm 0.89$ & $2.25 \pm 0.52$ & $4.05 \pm 0.94$ \\
PD $(\mathrm{mm})$ & $1.64 \pm 0.56$ & $1.51 \pm 0.65$ & $1.86 \pm 0.36$ & $1.49 \pm 0.51$ & $1.3 \pm 0.46$ & $1.5 \pm 0.55$ \\
PRC $(\%)$ & & & $73.2 \pm 15.58$ & $86.8 \pm 12.48$ & $76.9 \pm 16.77$ & $84.3 \pm 13.32$ \\
\hline
\end{tabular}

was found. Therefore, all centers were combined. Results for nine cases with no baseline keratinized tissue were statistically similar to the remaining cases in the same group. Therefore, these were included in the whole CTG group.

\section{Vertical Recession Defect}

At the 12-month follow-up, VRD decreased in the EMD group from $4.29 \mathrm{~mm}(\mathrm{SD}=1.10 \mathrm{~mm})$ to $1.18 \mathrm{~mm}$ $(\mathrm{SD}=0.72 \mathrm{~mm})$ and in the CTG group from $4.57 \mathrm{~mm}$ $(\mathrm{SD}=0.99 \mathrm{~mm})$ to $0.59 \mathrm{~mm}(\mathrm{SD}=0.55 \mathrm{~mm})$. VRD further decreased in the EMD group to $1.0 \mathrm{~mm}$ (SD = $0.72 \mathrm{~mm}$ ) at the 24 -month follow-up, but slightly increased to $0.7 \mathrm{~mm}(\mathrm{SD}=0.57 \mathrm{~mm})$ in the CTG group. Within groups, VRD changes were statistically significant compared to baseline $(P<0.001)$. However, differences were not significant between 12 and 24 months. There was an almost significant interaction $(P=0.054)$ between time and groups and a statistically significant difference between groups $(P<0.001)$.

\section{Probing Depth}

At the EMD sites, PD increased from $1.64 \mathrm{~mm}$ (SD = $0.56 \mathrm{~mm})$ at baseline to $1.86 \mathrm{~mm}(\mathrm{SD}=0.36 \mathrm{~mm})$ at the 12-month postoperative recording, but decreased to $1.3 \mathrm{~mm}(\mathrm{SD}=0.46 \mathrm{~mm})$ at 24 months. In the CTG group, PD remained nearly the same from baseline to the 12-month follow-up, but decreased to $1.5 \mathrm{~mm}$ $(\mathrm{SD}=0.55 \mathrm{~mm})$ at 24 months. Differences between groups for the 12- and 24-month recordings were statistically significant $(P<0.001)$ as analyzed by $t$ test. ANOVA with repeated measures showed a statistically significant interaction $(P<0.001)$ between time and groups. Changes within groups between 12 and 24 months were statistically non-significant.

\section{Height of Keratinized Tissue}

A statistically significant $(P=0.021)$ baseline difference in HKT was found between treatment groups. In the EMD group, HKT increased from $1.07 \mathrm{~mm}$ $(\mathrm{SD}=0.66 \mathrm{~mm})$ at baseline to $1.75 \mathrm{~mm}(\mathrm{SD}=0.59$ $\mathrm{mm})$ at the 12-month follow-up and $2.25 \mathrm{~mm} \mathrm{(SD=}$
$0.52 \mathrm{~mm})$ at 24 months. At the CTG sites, HKT increased from $1.65 \mathrm{~mm}(\mathrm{SD}=0.92 \mathrm{~mm})$ at baseline to $4.24 \mathrm{~mm}(\mathrm{SD}=0.89 \mathrm{~mm})$ at the 12 -month recording and slightly decreased to $4.05 \mathrm{~mm}(\mathrm{SD}=0.94$ $\mathrm{mm})$ at 24 months. Differences within groups ( $t$ test) between the 12- and 24-month follow-ups were significant in both groups (EMD: $P<0.001$; CTG: $P=$ $0.017)$. Values in the CTG group were significantly larger than the EMD group at both follow-ups $(P<0.001)$. ANCOVA (covariant preoperative HKT) showed a significant interaction between time and group $(P<0.001)$. HKT increased between the 12 and 24-month follow-up with EMD, but CTG values were more stable.

\section{Percentage of Root Coverage}

At the 12-month recording, PRC was $73.2 \%$ (SD = $15.58 \%)$ in the EMD group and $86.8 \%(S D=12.48 \%)$ in the CTG group. Differences between groups ( $t$ test) were statistically significant $(P<0.001)$. At the final evaluation, PRC increased to $76.9 \%(\mathrm{SD}=16.77 \%)$ in the EMD group and decreased to $84.3 \%$ (SD = $13.32 \%)$ in the CTG group. Differences between groups at 24 months ( $t$ test) were not statistically significant $(P=0.053)$. Differences between the 12 - and 24 -month recordings within groups were not statistically significant as analyzed with the paired $t$ test. ANOVA with repeated measures showed a statistically significant $(P=0.002)$ difference between groups for PRC.

\section{DISCUSSION}

The present study compared two periodontal plastic surgical procedures to achieve predictable coverage of exposed roots due to localized gingival recession. The subpedicle connective tissue graft procedure can be considered the gold standard because of its predictability and esthetic results. The coronally positioned flap procedure also has good results, is easier to perform, and avoids a second surgery to procure the donor tissue, thus reducing patient morbidity. Recently, root coverage using a coronally positioned flap, 
with or without a subepithelial connective tissue graft, was compared. ${ }^{41}$ No significant differences between the two groups were found, except a statistically significant increase in HKT where only a graft was used.

In a previous similar study ${ }^{37}$ with a 6 -month follow-up, root coverage was $77.4 \%$ in the EMD group and $84.1 \%$ in the CTG group. At 12 months, it was $71.7 \%$ and $87.0 \%$, respectively. Differences between groups were statistically significant. Differences between the 6- and 12-month vertical recession defect and percentage of root coverage recordings within each group were also statistically significant. In the present study, statistically significant differences in percentage of vertical root coverage were recorded between treatment groups. Extent of root coverage in both groups agrees with previous clinical research. ${ }^{20,30,31,41,42}$ Between the 12- and 24-month follow-ups, PRC decreased (2.5\%) in the CTG group, whereas it increased (3.7\%) in the EMD group. At 24 months, differences between groups only approached statistical significance. In a previous study, a similar "creeping attachment" recorded between 12 and 24 months in the EMD group was shown between 6 and 12 months in the CTG group. ${ }^{37}$ Changes within groups between 12- and 24-month measurements were statistically non-significant.

PD was greater in the EMD group than the CTG group (at baseline), although remaining shallow in both groups at 24 months. The final measurements showed a difference of $0.2 \mathrm{~mm}$ between groups. The validity of this finding should be evaluated in view of potential measurement errors in the range of 0.5 to $1.0 \mathrm{~mm}$. PD increase was not accompanied by a higher VRD. Studies have shown that recession coverage by the coronally advanced flap procedure does not result in pocket formation but rather tissue attachment on the previously exposed root surface. 20,22,23,28-32,41

Differences between groups in HKT were statistically significant $(P<0.001)$ and clinically important. Increase in the height of keratinized tissue following the subpedicle CTG procedure has been widely demonstrated. ${ }^{2,3,6,8,14,21,40,41}$ In the present study, the CTG was not completely covered by the recipient tissues, which apparently induced a larger increase. Changes in HKT following the coronally positioned flap procedure with the addition of EMD have recently been reported. ${ }^{30,32,35,37}$ Almost no change ${ }^{30,32}$ and even a slight decrease ${ }^{41}$ in HKT were observed when the same procedure without the addition of EMD was performed. This finding could suggest a long-term effect of EMD on gingival fibroblasts. ${ }^{43}$ In the present study, the increase in HKT was nearly $0.7 \mathrm{~mm}$ in the EMD group at the 12-month measurement, whereas at the final evaluation, an additional statistically significant $(P<0.001)$ increase of $0.5 \mathrm{~mm}$ was recorded; altogether, the HKT increase in the EMD group was $1.18 \mathrm{~mm}$ from baseline.

Histologic analysis following root coverage procedures has shown contradictory results, from a minimal amount of periodontal regeneration using different techniques $16,19,24,44,45$ to new connective tissue attachment. ${ }^{19,46}$ EMDs are effective in inducing periodontal regeneration in dehiscence type defects, ${ }^{33,34}$ but when combined with a subpedicle CTG, there were conflicting results. ${ }^{38,39}$ Histologically, periodontal regeneration following coronally positioned flap procedures has been found with the addition of EMD. ${ }^{36,38}$ In the present study, EMD was used to promote new attachment to denuded root surfaces. However, it is impossible to assess the nature of attachment through clinical examination. The larger number of female patients in both groups (CTG: $26 \mathrm{fe}$ males and 11 males; EMD: 18 females and 10 males) was due to the fact that consecutive cases were included in the study in all centers. Females apparently consult more for gingival recession than males. No statistically significant interaction between gender and treatment outcome was shown for any of the studied parameters.

Both treatments proved clinically successful. The CTG treatment showed a higher percentage of root coverage and HKT increase. EMD is a valuable, long-term effective treatment alternative to achieve root coverage together with an increase in HKT.

\section{ACKNOWLEDGMENTS}

The authors thank Rita Lazar (scientific editor, The Maurice and Gabriela Goldschleger School of Dental Medicine, Tel Aviv University) for editorial assistance and preparation of the manuscript and Ilana Gelerenter (statistical consultant, Department of Mathematics, Sackler Faculty of Exact Science, Tel Aviv University) for statistical analysis.

\section{REFERENCES}

1. Wennström J. Mucogingival therapy. Ann Periodontol 1996;1:671-706.

2. Edel A. Clinical evaluation of free connective tissue grafts used to increase the width of keratinised gingiva. $J$ Clin Periodontol 1974;1:185-196.

3. Edel A. The use of a free connective tissue graft to increase the width of attached gingiva. Oral Surg Oral Med Oral Pathol 1975;39:341-346.

4. Miller PD. A classification of marginal tissue recession. Int J Periodontics Restorative Dent 1985;5(2):8-13.

5. Langer B, Langer L. Subepithelial connective tissue graft for root coverage. JPeriodontol 1985;56:715-720.

6. Jahnke PV, Sandifer JB, Gher ME, Gray JL, Richardson AC. Thick free gingival and connective tissue autografts for root coverage. J Periodontol 1993;64:315-322.

7. Paolantonio M, Di Murro C, Cattabriga A, Cattabriga M. Subpedicle connective tissue graft versus free gingival graft in the coverage of exposed root surfaces. A 5-year clinical study. J Clin Periodontol 1997;24:51-56. 
8. Harris RJ. Root coverage with connective tissue grafts: An evaluation of short- and long-term results. J Periodontol 2002;73:1054-1059.

9. Greenwell H, Bissada NF, Henderson RD, Dodge JR. The deceptive nature of root coverage results. J Periodontol 2000;71:1327-1337.

10. Tal H, Moses O, Zohar R, Meir H, Nemcovsky CE. Root coverage of advanced gingival recession: A comparative study between acellular dermal matrix allograft and subepithelial connective tissue grafts. J Periodontol 2002;73:1405-1411.

11. Harris RJ. A short-term and long-term comparison of root coverage with an acellular dermal matrix and a subepithelial graft. J Periodontol 2004;75:734743.

12. Tinti C, Vincenzi G, Cortellini P, Pini Prato G, Clauser C. Guided tissue regeneration in the treatment of human facial recession. A 12-case report. J Periodontol 1992;63:554-560.

13. Pini Prato G, Tinti C, Vincenzi G, Magnani C, Cortellini $P$, Clauser $C$. Guided tissue regeneration versus mucogingival surgery in the treatment of human buccal recession. J Periodontol 1992;63:919-928.

14. Harris RJ. A comparative study of root coverage obtained with guided tissue regeneration utilizing a bioabsorbable membrane versus the connective tissue with partial-thickness double pedicle graft. J Periodontol 1997;68:779-790.

15. Tatakis DN, Trombelli L. Gingival recession treatment: Guided tissue regeneration with bioabsorbable membrane versus connective tissue graft. J Periodontol 2000;71:299-307.

16. Weng $\mathrm{D}$, Hürzeler $M B$, Quinones $C R$, Pechstadt $B$, Mota L, Caffesse RG. Healing patterns in recession defects treated with ePTFE membranes and with free connective tissue grafts. A histologic and histometric study in the beagle dog. J Clin Periodontol 1998;25: 238-245.

17. Jepsen K, Heinz B, Halben JH, Jepsen S. Treatment of gingival recession with titanium reinforced barrier membranes versus connective tissue grafts. J Periodontol 1998;69:383-391.

18. Zucchelli G, Clauser C, De Sanctis M, Calandriello M. Mucogingival versus guided tissue regeneration procedures in the treatment of deep recession type defects. J Periodontol 1998;69:138-145.

19. Cortellini P, Clauser C, Pini Prato G. Histologic assessment of new attachment following the treatment of a human buccal recession by means of guided tissue regeneration procedure. J Periodontol 1993;64:387391.

20. Wennström JL, Pini Prato G. Mucogingival therapy. In: Lindhe J, Karring T, Lang NP, eds. Clinical Periodontology and Implant Dentistry. Copenhagen: Munksgaard; 1998:550-596.

21. Harris RJ. GTR for root coverage: A long-term follow-up. Int J Periodontics Restorative Dent 2002;22:55-61.

22. Matter J. Free gingival graft and coronally repositioned flap. A 2-year follow-up report. J Clin Periodontol 1979;6:437-442.

23. Trombelli L, Tatakis DN, Scabbia A, Zimmerman GJ. Comparison of mucogingival changes following treatment with coronally positioned flap and guided tissue regeneration procedures. Int $J$ Periodontics Restorative Dent 1997; 17:448-455.

24. Lee EJ, Meraw SJ, Oh TJ, Giannobile WV, Wang HL. Comparative histologic analysis of coronally advanced flap with and without collagen membrane for root coverage. J Periodontol 2002;73:779-788.

25. Amarante ES, Leknes KN, Skavland J, Lie T. Coronally positioned flap procedures with or without a bioabsorbable membrane in the treatment of human gingival recessions. J Periodontol 2000;71:989-998.

26. Allen EP, Miller PD. Coronal positioning of existing gingiva: Short-term results in the treatment of shallow marginal tissue recession. $J$ Periodontol 1989;60: 316-319.

27. Harris RJ, Harris AW. The coronally positioned pedicle flap with inlaid margins: A predictable method of obtaining root coverage of shallow defects. Int $J$ Periodontics Restorative Dent 1994;14:228-241.

28. Bernimoulin JP, Lüscher B, Mühlemann HR. Coronally repositioned flap. Clinical evaluation after one year. $J$ Clin Periodontol 1975;2:1-13.

29. Tenenbaum H, Klewansky P, Roth JJ. Clinical evaluation of gingival recession treated by coronally repositioned flap technique. J Periodontol 1980;51: 686-690.

30. Hägewald S, Spahr A, Rompola E, Haller B, Heijl L, Bernimoulin J-P. Comparative study of Emdogain and coronally advanced flap technique in the treatment of human gingival recessions. A prospective controlled clinical study. J Clin Periodontol 2002;29:35-41.

31. Modica F, Del Pizzo M, Roccuzzo M, Romagnoli R. Coronally advanced flap for the treatment of buccal gingival recessions with and without enamel matrix derivative. A split-mouth study. J Periodontol 2000; 71:1693-1698.

32. Cueva MA, Boltchi FA, Hallmon WW, Nunn ME, Francisco Rivera-Hidalgo F, Rees T. A comparative study of coronally advanced flaps with and without the addition of enamel matrix derivative in the treatment of marginal tissue recession. J Periodontol 2004;75: 949-956.

33. Heijl L. Periodontal regeneration with enamel matrix derivative in one human experimental defect. A case report. J Clin Periodontol 1997;24:693-696.

34. Hammarström L, Heijl L, Gestrelius S. Periodontal regeneration in a buccal dehiscence model in monkeys after application of enamel matrix proteins. J Clin Periodontol 1997;24:669-677.

35. McGuire MK, Nunn M. Evaluation of human recession defects treated with coronally advanced flaps and either enamel matrix derivative or connective tissue. Part 1: Comparison of clinical parameters. J Periodontol 2003;74:1110-1125.

36. McGuire MK, Cochran DL. Evaluation of human recession defects treated with coronally advanced flaps and either enamel matrix derivative or connective tissue. Part 2: Histological evaluation. J Periodontol 2003; 74:1126-1135.

37. Nemcovsky CE, Artzi Z, Tal H, Kozlovsky A, Moses O. A multicenter comparative study of two root coverage procedures: Coronally advanced flap with addition of enamel matrix proteins and subpedicle connective tissue graft. J Periodontol 2004;75:600-607.

38. Sculean A, Donos N, Reich E, Brecx M, Karring T. Healing of recession-type defects following treatment with enamel matrix proteins or guided tissue regeneration. A pilot study in monkeys. $J$ Parodontol Implantol Orale 2000;19:19-31.

39. Rasperini G, Silvestri M, Schenk RK, Nevins ML. Clinical and histologic evaluation of human gingival recession treated with a subepithelial connective tissue graft and 
enamel matrix derivative (Emdogain): A case report. Int J Periodontics Restorative Dent 2000;20:269-275.

40. Carnio J, Camargo PM, Kenney EB, Schenk RK. Histological evaluation of 4 cases of root coverage following a connective tissue graft combined with an enamel matrix derivative preparation. J Periodontol 2002;73:1534-1543.

41. Carvalho Da Silva R, Joly JC, Martorelli de Lima AF, Tatakis DN. Root coverage using the coronally positioned flap with or without a subepithelial connective tissue graft. J Periodontol 2004;75:413-419.

42. Harris RJ. The connective tissue and partial thickness double pedicle graft: A predictable method of obtaining root coverage. J Periodontol 1992;63:477-486.

43. Keila S, Nemcovsky CE, Moses O, Artzi Z, Weinreb M. In vitro effects of enamel matrix proteins on rat bone marrow cells and gingival fibroblasts. J Dent Res 2004; 83:134-138.
44. Woodyard SG, Snyder AJ, Henley G, O'Neal RB. A histometric evaluation of the effect of citric acid preparation upon healing of coronally positioned flaps in nonhuman primates. J Periodontol 1984;55:203-212.

45. Majzoub Z, Landi L, Grusovin MG, Cordioli G. Histology of connective tissue graft. A case report. J Periodontol 2001;72:1607-1615.

46. Goldstein M, Boyan BD, Cochran DL, Schwartz Z. Human histology of new attachment after root coverage using subepithelial connective tissue graft. J Clin Periodontol 2001;28:657-662.

Correspondence: Dr. Carlos E. Nemcovsky, Department of Periodontology, School of Dental Medicine, Tel Aviv University, Tel Aviv, Israel. Fax: 972-3-6409250; e-mail: carlos@post.tau.ac.il.

Accepted for publication June 27, 2005. 